\title{
Methodology of the Austrian School of Economics from the perspective of Georg Henrik von Wright's philosophy of science
}

\author{
Radu ISAIC \\ Bucharest University of Economic Studies, Bucharest, Romania \\ isaicradu@yahoo.com
}

\begin{abstract}
Through this article we will try to get into the way of thinking of one of the most important economic schools, namely the Austrian School. Over time, many mistakes have been made by various economic schools because the fundamentals of thinking were not clear or the concepts used were not properly defined. Here we will try to clarify the foundation in general of the socio-human sciences and in particular of the mentioned school. Building theories or opinions on a fragile foundation will certainly give rise to a friable architecture. Among the various philosophers who have approached science, we believe that von Wight has a direct and clear approach to the type of human social thinking. From the information we have we do not know an approach similar to this article. The Austrian School has hitherto been understood as a methodology from the perspective of Aristotelianism. The question is whether a new perspective can make more sense. The methodology of presenting the article is narrative argumentation. The questions we try to answer in the conclusions are those related to understanding the present moment and discerning the future moment through the fog. The conclusions will be critical regarding the use of mathematics in the socio-human sciences, and the socio-human sciences must be understood only from the perspective of human motivations and intentions. Clarifying the starting point in economic thinking makes us more modest in drawing conclusions and making predictions about the future.
\end{abstract}

Keywords: Austrian School, methodological monism, methodological dualism, explanation - causal, understanding - intentional.

\section{Introduction}

\section{Introduction to the Austrian School}

The Austrian School of Economic Thinking is the first economic school to think of the individual as an active actor. Actor who makes decisions, and the expression of responsible active decisions is the market. The market is a materialization of the free will of individuals and their responsibility for the decisions they make (Smith, 1994).

A.S. considers that the experiences of the individual are essential and especially the thinking based on certain values. The experiences of each individual plus the values, ideas, beliefs lead to a free, non-deterministic behavior of individuals and to difficulties in anticipating their actions.

A.S. logic is Aristotelian ontological, logic based on the essences of the economic field. These essences must be identified and evaluated. The economic world is a real world that can be known by a deductive logic, so the economic world is an independent world (not determined by thinking). The essences are universal that can be established by an aristotelian (Menger, 2016; Rothbard, 1977; Hayek, 1973) or kantian (Mises, 1966,) apriorism. The A.S. method is called praxeology or the science of human action.

The other facet of A.S. methodology is methodological individualism. This means that the actions of individuals are teleological can only be understood from the perspective of individuals. Individuals must be viewed from the perspective of mutual connections between 
them. The A.S. opposes the introduction of physical science methods in economics, recognizes the importance of ignorance about the results of human action and is interested in the individual, market, institutions.

A.S. introduced the notion of spontaneous order, order based on the actions of individuals that leads to the emergence of institutions. The emergence of institutions can have intentional causes or not. Human actions are conscious and pursue goals. Menger (2016) makes an analysis of how individuals' actions build institutional regularities. The actions of individuals in a society are only seemingly independent, they are formed on a background or value context. A.S. followers seek universal and necessary laws that are valid and at the same time empirical regularities. A.S. deals mainly with the study of natural, organic institutions, which appeared as a result of natural processes. In contrast to the natural institutions are the pragmatic ones that appeared as a result of rational establishment plans (Mises, 1966).

During the exchanges that take place between people, their value judgments materialize and the ordering of priorities takes shape. Priorities turn into information, information that producers evaluate and turn into resource allocation action. But this phenomenon appears impossible in the absence of markets, where the encounter between rarity and intensity takes place (Rothbard, 1997).

Hayek is the economist who has made key contributions to setting the boundaries of knowledge in market-related phenomena. There is group intelligence; an individual knows little but relies on the intelligence and knowledge of the group. The group as a whole, has intelligence and knowledge that will make it adapt to the environment. Evolution means that conscious knowledge becomes an automatic action within spontaneous institutions (Hayek, 1949).

Austrians are the first to talk about the important place that the concept of human action should occupy in the human sciences. For Mises, the starting point is the idea that people act consciously following a goal, so they start from a series of self-evident axioms, more precisely a priori, from which statements are deduced with a high or absolute degree of certainty. That is why it is very important to choose the premise, the starting statement; it must necessarily be universally true, its certainty absolute. The way in which the starting sentences are established can be done in two ways. The first is Aristotelian, reality is observed and forms are identified the essences of reality from which the following truths with logical necessity are deduced. The second is Kantian, the forms are in our minds and have nothing to do with reality (Rothbard, 1977).

Mises prefers the second type and states that there are a priori synthetic truths (eg the axiom of action), ie truths about the reality we know without the need to come into contact with reality (Mises, 1981). Rothbard approaches the axiom of action from the Aristotelian vision as a form of empirical reality. Rothbard also attacks empiricism by stating that reasoning must form theory, not mere historical empirical research (Rothbard, 1977).

A.S. is based on the concept of the individual on his life and consciousness, hence the many ethical implications.

\section{Introduction to von Wright's theory}

Methodological monism. By knowing the universal and necessary laws we can explain both the past and make predictions. We need the laws of the universe and a state of affairs of the components of the universe. To know the future we must have an accurate description of the components of a physical system. It uses deductive-logical thinking and the orientation of thinking from cause to effect. Between cause and effect are inserted different types of reasoning 
related to the identified universal laws. Everything in the universe is linked in a determined and absolutely necessary way. It is used in physics, chemistry, geography and more diluted as ideal in biology.

Methodological dualism. In the case of the socio-human sciences, in order to understand the events related to human action, it is necessary to know the aims and motives of the human actors involved in a certain event. We want to separate the concept of reason from the concept of purpose. We consider that the reason is the starting point of an action (escape of pain), and the goal is the end point of an action (achieving satisfaction - pleasure). The laws in the case of human sciences are more laws of tendency, approximate laws, of nuance, of direction. Laws for man are not strict laws cause effect. The cause, the effect, the justification between them are approximate, probabilistic. They belong to purposes and motives, some obvious and conscious, others approximate and inarticulate (Wright, 1971).

In both sciences we must start from what we consider to be a stranger and then describe him. We must keep in mind what is unknown, the problem, what arouses our curiosity, what we do not know, what event or object we can not integrate into our knowledge system and describe it clearly and clearly. The starting point is negative. The description tells us what we do not know and what it means (Chisholm, 1977).

In the physical world, a simple description of a thing or event aims at a causal explanation. In the world of human actions, the attempt to achieve the purpose of a human event refers to a teleological understanding.

\section{We will distinguish two concepts}

First: explanation for the physical type description, ie cause effect with logical judgment type inserts.

Second: understanding for the human description of an event given the purpose of human action: Understanding is an assimilation of the motives and purposes of the individuals who acted and produced an event that we try to describe. Understanding is related to empathy with the reconstruction in the mind of the one who wants to know the architecture of feelings of the one who wants to be known. The agreement is related to the decoding of a symbol, sign or religious ritual.

\section{There are two types of determinism}

The first is strictly causal. It is believed that the future can be accurately predicted. The future appears in a world of strictly necessary universal laws starting from a factual situation. If we cannot accurately predict the future, it is due to the fault of scientists who do not know the laws of the universe completely or do not know the exact position of the components. A causal relationship in the physical sense means a relationship of strict dependence.

The second type of determinism is such as understanding - intelligible. That is, we can describe an event in the case of its internal mechanisms after the event has taken place; we can only understand trends. In the case of people we can only know about their goals, intentions, knowledge, possessions, attitudes and skills. That is why the understanding of an event occurs after it has taken place.

In human actions, an aspect that should not be neglected are the institutions and laws of the city where a person operates. We cannot describe a person's action without analyzing his or her conduct vis-à-vis the legislative framework. Laws are a useful scheme, a precious framework through which to decode people's actions. The behavior of an individual or group of individuals 
in a certain phase of development of institutions and laws has certain regularities, certain stable aspects so that based on them we can make predictions. These fixed aspects of human behavior must first be identified and then linked to the legislative framework at a certain historical moment. The big question: are there regularities of human action independent of the legislative situation, regularities that are absolute, universal and necessary like breathing?

The laws of the city from a certain historical moment can lead to the establishment of a certain predictability of simple and relatively unimportant level for a scientific study. Over this simple anticipation we can superimpose the intentions of individuals from a certain stage of social development. Together they can give an understanding of past human action. For the future we can draw certain trends from understanding people's intentions.

\section{Literature review}

\section{Traditions in scientific thinking.}

Science consists of two activities. One is setting events, and the other is raising theories. Among the purposes of science we can list firstly the ability to anticipate future events especially in the physical sciences (Bratianu \& Bejinaru, 2019) and secondly to explain / understand past events especially in the humanities.

The intelligibility of science has two traditions. One is Aristotelian and one Galilean Newtonian. Aristotelian intelligibility is a finalist teleological understanding, Galilean-Newtonian intelligibility is a mechanistic causal explanation.

For Aristotle, reflective understanding is important, not the methods of inducing generalization from the particular to the general. For Aristotle, the final and possibly the formal causes are important. An event becomes intelligible by knowing its purpose. The final cause is more important than the efficient cause, ie the engine that performs it.

The field of teleological understanding is divided into two: The field of function and system concepts in the biological sciences and the field of intentionality in the human sciences. The understanding aims at a stronger connection of the basis of the explanation with the object of the explanation than of the simple successive joining of the two.

In the humanities, the laws of behavior link the type of action to human motives. Human action has a cause, this is the reason and so the first seeds of the deterministic theory of human behavior appear, and freedom of will is necessarily determined by the birth of motives. Science must lean on the source of the birth of motives.

In the humanities, the laws of behavior link the type of action to human motives. Human action has a cause, that is the reason. Thus appear the first seeds of the deterministic theory of human behavior. Freedom of will is necessarily determined by the birth of motives. Science must lean on the source of the birth of motives.

In the physical sciences there is a clear method in the explanation: that of subsuming the laws. In the humanities, the practical syllogism is preferred for understanding (teleological explanation). The practical syllogism involves three stages. The first stage is the major premise or purpose of the action. The second stage is the minor premise that is the means to achieve the goal. The third stage (and the last) conclusion, in which we use the means to achieve the goal.

\section{The effective cause, the material cause}

From the beginning of thinking, the terms cause and effect are used in an empirical sense, and the terms of basis and consequence in a logical sense. The cause generally has an action meaning refers to a movement, displacement and in science depends on experiment. The causal 
explanation eventually led to the emergence of the concept of laws and principles. The notion of time must be inserted in the thinking of causality. The human mind connects causality to the notion of succession that changes over time (Descartes, 1990).

Also in causality we must distinguish causal analysis from causal explanation. The first appears in a coherent theoretical network system and the connections and relationships between the nodes of the explanatory system must be highlighted. Nodes that represent notions or ideas. The mechanism of coagulation of a theoretical system must be unraveled and analyzed in pieces and as a whole. Second, the causal explanation is how we link an empirical fact to a current system of reasoning.

In ordinary and even scientific thinking, the cause is thought of as an element that produces an effect through action and is responsible for what it does. We can say that an analogy of human behavior is used; that is, man acts, implicitly man causes. Causes move a system closer or closer to a virtual equilibrium point. In the social sciences the point is thought in terms of civilization and the moment of evolution of civilization. Cause at origin is a judicial word that refers to guilt.

Due to the analogy with human behavior and the thinking of the concept of causality as the force responsible for something that produces, the result was the belief in obscure forces for various purposes. Over time, causality has become a mechanism determined in its function by its own composition. But causality remains linked to the notions of action, movement and especially the notion of production.

In human behavior, doing things is distinct from causing things. We can do something that causes something else. We can perform an action that has a certain result that in turn becomes a cause for something; that something becomes an effect or consequence of that cause. A man acts, the result of the action is a state of fact; this state of affairs produces consequences (effects) independent of the initial human action.

Within the notion of cause: the action and its result are logically linked to each other, it is not possible without each other. The mechanism of binding to each other is internal and not external. To take action is to set in motion a system of relationships. A state of affairs changes and thus another state of affairs is built. To perform a production action means to pass a system through at least two states and to have a conditioning relationship between the two states. Between two stable states of a system are transition states or simple change states. A state of a system in order to acquire certain noticeable modified aspects, must have a critical mass of changes within its properties.

When we talk about causality we have to talk about closed systems. Causality occurs in closed systems and in which we have a reference system; something to refer to. In science we need to identify and isolate systems and possibly act within systems in their normal causality.

In the case of human activity when we say that something is a cause for certain effects, we are actually saying that people produce a cause which in turn produces certain effects. The cause can also be thought of as a necessary condition possibly sufficient for the effect. A human action includes in it many causalities; they cannot be fully identified either at the level of concept or in fact. A human action to produce causes does not necessarily have to be performed by a free agent. Man only through the actions he performed came to think of the concepts of cause and effect.

At a careful analysis in the human sciences between freedom and causality there are certain antagonisms, frictions. One limits the other. If I don't have certain freedoms, I can't bring certain causes. 
The man in a state of complete passivity and if he is able to record then he observes obligatory sequences of events. He can put a relationship between them and extrapolate it in time to infinity before and after. But the sequence refers as we have mentioned to closed systems relative to a certain reference system; so extrapolations are risky.

Identifying the causes includes a passive and an active action. The active component is to produce causes by building an initial state. The passive component is the observation of what is happening inside the car (the system under observation).

PICBE | 1015

\section{The final cause}

In classical scientific thought, causality is antagonistic to the teleological explanation. The look of causal explanations is to the past. There must be a real illogical connection between cause and effect. The validity of the cause-effect link will determine the validity of the explanation.

In the case of the humanities, teleological explanations are future-oriented thinking. And in this type of causality there must be a real connection not of a logical nature between the phenomena explained. But the connection in the case of teleological explanations is indirect, not as in the case of simple causality where it is direct. In the case of the human sciences, the purpose of the explanations is human behavior, behavior that occurs because of something.

The human behavior that is required to be explained causally has two components. One is the inner motivation of the causative agent and the other is the outer manifestation of the behavior. There may be no similarity between the two, sometimes the inside differs from the outside. There may be a time gap, sometimes quite large, between the inner component and the outer component of the causal explanation in human actions. The inner component may not have continuity in the purely actional behavior of man.

In our case we are interested in the connection between the two components and especially in the external action component. Many of the consequences of an action are unintentional and may be contrary to the original goal. At the same time, a human action can be the product of an event that did not have a purpose.

In fact, all human actions can be understood if they fall under the umbrella of the notion of intentionality. Otherwise there is no connection between the various actions. We can establish a logical relationship between facts and understand something of the sequence of human deeds, only if we constantly consider the notion of reason. There is no necessary relationship between the two types of causality, ie causality between real phenomena and logical causality.

A human action can have several stages. But in front of the first stage we have to find the motivation, ie an object of intention, which the agent wants to make, a desired result to be achieved as a result of the actions. Before an action are the causal requirements, and after an action are its consequences. The consequences can have different deadlines and can be intentional and unintentional. A distinction must be made between motivational action and motivation. The teleological explanation is the highlighting of motivation. The question is how to relate the intended consequences to the anticipated consequences. Another discussion is the type of motivation - the goal that pushes the present into the future or the one that attracts the future into the present. We believe that quality entrepreneurship pushes the present into the future.

Since Hume, science has distinguished between cause and effect on the one hand and reason and consequence on the other (Hume, 1987). The connection between cause and effect does not have to be logical, the implications between the two are causal (factual) implications; there are logical implications between reason and consequence. The motivations for a behavior must be included within the behavior and not left out of the type of behavior. Behavioral 
explanations must be seen in a wide range of purposes and ideas. There must be a context of action consisting of knowledge, desires, ideas, in order to understand a certain behavior. So that we are able to insert a pertinent motivation in the explanation.

In the teleological explanations we start from conclusions to premises. A behavior is fulfilled and goes on the logical thread upstream. In the socio-human sciences a man cannot be an observer of his own action because he does that action, he produces it, he is not a mere spectator. Without understanding the motivation - the intention of an act, we cannot understand that act and its consequences.

\section{Formal cause}

Understanding teleological acts must be accompanied by understanding the intentions (motives) of the actions. We can consider a closer analysis of a certain hierarchy in the reasons for human actions. A certain reason must be properly interpreted in the light of its significance in comparison on the one hand with the context of the values of the person performing the act and on the other hand with the social, institutional context in which he carries out his activity.

Explaining human actions means in our option to limit yourself to superficial causal elements. To understand is the descent into the deep elements of the actors' intention, their values, viewed both as individuals and as a group. Understanding is a reinterpretation of the explanation in the light of the reasons. Understanding places human actions under a new concept of explanation.

The explanation sees something similar in the sequence between two events. That is, something of a phenomenon is preserved in the phenomenon that follows it. Something in the phenomenon called cause produces (acts) the effect phenomenon without the need to preserve the latter something. Understanding sees the significance of human action. A human action means something to the actors involved in it, it is not a simple sequence of events.

In the explanations of the socio-human sciences the first step of the explanations is to identify the non-human causes of the action; the next step is how they affect human inner states, (motivations). Then as a last step the non-human phenomena that occur after individuals act according to their motivations. And the cycle continues. There may be a conceptual factual connection between the last and the first stage of the human causal process, but not a logical one. We can understand the transition from one stage to another, but this transition does not necessarily have a logical need, but is a factual transition.

In an explanation of historical narrative type (typical of the human sciences) for the beginning, the factual situation is described in terms of some characteristics considered essential in relation to the subsequent development of events. This first explanation can give the material and human context of action. A deed deemed event is inserted in the description suite. The change in the intentions of the person or group of persons in question is then narrated. Any human action must be carried out in stages. Between stages it is necessary to insert events that orient the story in a certain direction. The insertion of events does not have a logical but factual basis and the orientation of the action depends on the partial motivations in stages. No stage should be considered logically absolute but only relative to a context and certain motivations. The sequence of events can always be interrupted and change direction. Inferences in the history of human actions are practical and have a motivational need.

The conclusion is obvious: physical causation differs from human causation. The purpose of the first is anticipation, predetermination; the purpose of the second is understanding, post-determination. But also in the physical sciences and in the human sciences we do better 
with explanations and understandings when we focus on the behavior of a large number of elements; elements that we understand little at the individual level.

Anticipation or understanding works well at the macro level and little or no component level, as the Austrian School says. There is a determinism at the level of the action of large groups of individuals and a clear indeterminism at the level of the individual. How the two determinisms reconcile logically will remain a mystery. We will know that this year $1 \%$ of the population will commit suicide, but we will never know if this person will do it or not. If the actions of any individual in life are motivated by something, they have a purpose then the sum of all the action of the individuals in a group has a purpose. Which means that somehow the group's actions are determined.

It is easy to explain an individual's actions in terms of their motives, but understanding a group's behavior in terms of group intentions is complicated and problematic. It is difficult to identify and describe the intentions of a group, and they will be constantly discussed and re-evaluated.

When it is declared that the behavior of an individual or group is rational because the intentions (goals) are understood, we actually enter a dangerous area. The question is automatically asked whether an individual's behavior is determined by his goal, where is his free will and moral responsibility? A man becomes morally responsible when he is aware of the consequences of his actions.

Theories are divided from the latter point of view into: firstly, weak rationalist theories that explain the behavior of a single individual in terms of his goals (and the action of his mind) and secondly, theories of absolute rationalism that explain the course history through a kind of objective and absolute idea. The Austrian school is part of the first model.

\section{Methodology}

\section{The A priori of the Austrian School}

Mises was a follower of Kantian a priori, at least at the declarative level. For him, the concept of action is a priori, ie it has nothing to do with experience, that is, with empirical real life. It has the same epistemological status as the law of cause and effect or the idea of time. They are structures of the human mind necessary to understand absolute reality. More precisely, reality can only be known through the instruments of the mind. These tools translate reality into a form cognizable by the human mind. The deep structures of the human mind overlap or impose themselves on reality. Mises accepts only the axiom of action as a synthetic a priori sentence, the other axioms are empirical in a broad sense and are subject to the essence of Aristotelian apriorism. Mises asserts the certainty of the apodictic axiom. For Mises, praxeology is a law of thought.

H.H. Hope states that the following categories are involved in the axiom of action: values, goals, means, preferences, choices. He also states that actions cannot be identified at the level of perception; so that the axiom of action is not derived empirically and cannot be contradicted because to contradict it means to act. A priori is a relationship between concepts, the world is intelligible only in the presence of a mind.

Rothbard and Hayek are followers of Aristotelian apriorism, ie the formal essences or causes are identified by the human mind in the unfolding of reality and are then described and analyzed. Empiria is not reduced to an isolated set of data but contains in their structure a certain connection, a connection that Aristotle identified with the formal cause - the essence. For Aristotelians there are two planes, one ontological and one psychological - epistomological. The real correlation between the two takes place in knowledge. That is, the psychological plan 
identifies the real forms that exist and is not just a way to establish mental mechanisms; mechanisms that we forcefully impose on reality. The act of knowledge is a cognitive synthesis in which there is equality between the two planes. For Rothbard, praxeology is a law of reality. Although at first sight this type of legitimacy may seem a posteriori, it differs so much from empiricism that it can be called a priori because the laws of essences cannot be false, they are reached by thinking and they do not depend on a certain context (they are universal).

In conclusion, in the Aristotelian sense the axioms of praxeology are built on empiricism - experience, they are self-evident. The axiom of action is a real empirical experience and has a record of thinking - reflective. Obviously, it means that everyone who reads them accepts them as included in their previous unexplained knowledge. An obvious knowledge in itself cannot be questioned. To confirm something obvious is equal to making obvious, something that is obvious. To deny human action means to already take action.

\section{Results and discussions \\ Praxeology}

It is based on the assertion that individuals act consciously towards precise and clear goals. This assertion is considered an axiom on which the A.S. building stands. Other basic assertions are the distinctiveness of individuals and the appreciation of free time as valuable. Among the implications of the axioms is the finality of human actions, and the actions are teleological. The means are consciously chosen for the fulfillment of conscious purposes. A chosen goal represents a value for an individual, it has a certain importance. Individuals have value systems that direct them in activities. The fact that an individual chooses certain means for certain purposes means that he also has certain technological knowledge.

Human actions take place over time in the form of a succession of actions that take steps towards a goal. If the goals were met instantly, the reason for the action would disappear. By action one state of affairs is modified by another; an undesirable state is changed to a desirable state. The future is unknowable because otherwise human actions would be worthless. The science of human action involves the approximate ignorance of the future. Individuals make plans to use certain means to achieve certain goals, because the future is partly certain and partly uncertain (Say, 1964).

Action implies that means and ends are scarce. Otherwise, the goals would have already been achieved and human action would no longer be necessary. Abundant resources are not the subject of the action no longer have the role of means. Mankind will never reach absolute abundance, even in paradise time remains limited; we perform an action at a certain point in time. Physical limitations also lead to satisfaction; we enjoy a limited number of goods at a time.

From the axiom of human action we could logically deduce some implications. These implications cannot be tested historically or statistically, nor is it necessary to do so, because the truth is already established a priori.

There are two issues that need to be addressed. The first, the ontological and epistemological status of the action and the second, the logical mechanism of deduction. In praxeology the axioms are obviously true and have meaning. From the axiom we deduce logically with the help of sentences - new ideas, truths. Every sentence used for deduction has meaning as opposed to simple mathematical symbols. The axiom of action is self-evident and is an axiom for the contradiction of which the axiom itself is used. The axiom of consciousness is another example and is affirmed by introspection and by the fact that in its contradiction consciousness is used. 
Praxiology is built on methodological individualism. Which means that only individuals act, think, feel. Praxeology has a deep respect for the uniqueness of historical facts. A.S. thinks totally opposite to the empirical positivism that assimilates people to atoms, atoms subject to quantitative laws. A.S. rejects mathematics in the social sciences because it rejects the existence of the notion of quantitative constants in human action (there are no constant relationships). The economic law is neither confirmed nor refuted by concrete facts; instead the law where it applies automatically explains. The facts are those that indicate the statements in the results of the law (Kirzner, 1996).

\section{Praxeology as a method and Methodological Individualism.}

The usual model of science has four stages. First, certain empirical regularities are identified. Second, hypotheses are constructed that explain the regularities. Thirdly, consequences must be drawn to be observed or experienced later. Fourth, more and more general statements can be deduced from the hypotheses.

In economics, on the other hand, it starts with a statement of great generality. This statement is self-evident and serves as an axiom; axiom that expresses necessary correlations between social states. Starting from the axiom, a whole theoretical system is built on the basis of logical deduction. From the apodictic axiom to the empirical law.

The axiom of human action represents the nature of human action. People act consciously, have goals according to which they order their means and act. People have values according to which they act and according to which they prioritize their needs. The certainty of the axiom of action is connected to the knowledge based on introspection, introspection made by each individual. The axiom of human action provides a foreknowledge of common historical events. People act to achieve goals implies scarcity of resources; rarity is costs that in turn involve a monetary system. Human action is universal, action is motivated by something and is universal. Human action is different from the unintentional mechanical behavior of atoms. Economic theory deals less with human intentions and choices and more with people's involvement in actions (Mises, 2006).

One of the mental mechanisms by which deductions are made from the axiom of human action is the use of the mental experiment. In everyday life, certain variables cannot be kept constant and others cannot be modified in order to be able to observe what is happening. Instead, in mental experiences one can build desired scenarios, scenarios where we can predict and analyze the results. Narrative arguments, verbal logic are used and the influence of one variable on another is studied mentally. The laws thus deduced are necessarily qualitative because individuals have goals and make decisions based on preferences.

People are constantly changing their preferences. Material and cultural civilization worldwide is dynamic and affects elections. Thus, the decisions of individuals cannot be correctly anticipated. Economists are not prophets, they only indicate what might happen in the course of one event or another. On the one hand in praxeology we have deductive laws from a priori axioms, on the other hand we have a collection of unique facts: economic and historical.

People build history through conscious decisions, they do not submit like lifeless particles to irrational mechanisms. Historical events are unique and the result of complex forces. There are similarities between historical events, but not homogeneity, so there can be no social laws similar to the laws of physics. To explain a historical phenomenon, the economist uses scientific knowledge plus the reasons for actions. Praxeologists use past and present knowledge in anticipation, ie causal antecedents plus axiomatically deduced laws. The future can only be 
predicted as a trend, free will alters any prediction, people's decisions are free and the consequences unforeseen. Statistics do not show the source and consequences of the facts (Mises, 2009).

In praxeology we cannot introduce excessive simplifications as in physics, because the conclusions would be strongly altered and distorted. Praxeology deals with the qualities of individuals, and mathematical calculations would be futile in this case, it would excessively simplify a rich and complex world. So the favorite experiment of praxeologists is the mental one.

A.S. bases its theory on the ontological plane. The starting point is logical but with roots in empiricism, and the validity of the statements is also logical. The laws of A.S. go beyond the data and the concrete, having a high level of generality and necessity. A.S. explains events through the mental actions of individuals.

The fundamental principle of methodological individualism states that man is endowed with reason, he perceives through the senses, feels, appropriates values, makes decisions and acts in order to achieve a goal using various means. Collectivities are only emerging structures of the types of organization of individual actions.

We must return to the real man, the one who acts consciously whose thoughts, deeds, feelings are the foundation of the real world. The mental states of the real man are at the origin of his attitude towards the social context.

The study of human action is done with the help of reason, human beings have free will, are responsible for their actions and have the consciousness of choosing their actions. To ignore human free will means to ignore reality.

If a man has goals he must choose his means. The steps taken by a man towards the goal are part of the consciously chosen means. Man is not born with a foreknowledge of his goals, they must choose them and must also have the responsibility to choose the means to achieve the goal. Man must learn how and why he must choose according to his context and values. In the absence of conscious choice, the human sciences would disappear.

Through introspection man recognizes his responsibility and the consciousness of his free choice, based on a free will. The sciences have never proven the validity of determinism in the case of human action. The need to obey the laws of nature has nothing to do with his freedom but with his power. Determinism is valid for the physical world, free will is true for human nature; each acts according to his nature. The cause of human action is a combination of mental activity based on free will and external events.

The study of human action is clarified by the understanding that freely adopted ideas should build social institutions and not otherwise. Human actions are provoked either by his free will or by forces external to his will.

In physics the variables are connected, but they are not causes for themselves but their cause is external due to interactions with other entities. In the case of human actions, the cause is within the individual represented by the free will of conscience, his free will. Mathematical analysis in human action cannot be used because it requires continuity, and human action is in small, discrete and finite steps.

Equilibrium in economics, a concept brought from physics, is an illusion. Man acts permanently to eliminate discomfort. He acts by notifying problems and implementing solutions. He observes unsatisfied needs and organizes the material world in order to satisfy them. People are experiencing a permanent imbalance, social nirvana is just a game of the mind.

In praxeology we will go to the explanatory path with the help of axioms. Individuals are causal agents, their mental activity will determine their action and decisions made. Their mental 
activity is based on free will. From the basic axioms we start by deduction by introducing auxiliary axioms to limit the area of research. The inner feelings of individuals are dynamic, in a permanent change, so that experiments have a negligible relevance. In conclusion the most relevant method of studying human activity is axiomatically deductive, the conclusions of this method are necessarily true. Example: if the action shows the individual's preference then the voluntary exchange between two people indicates the expectation of benefits by both people. The result of an action must be a preferable state to the previous one because otherwise the action would not have made sense. Preferences materialize through action through the exchanges in which a person is engaged. The order of preferences is not constant over time (Rothbard, 2008).

\section{Value judgments}

Ethics is the science that deals with the system of values of individuals. Ethics must provide standards for an analysis of an action using value judgments. Praxeology cannot by itself establish value judgments. It studies people's action and not the ethical value of this formal cause of action. The praxeologist knows that people act according to meanings, but he does not introduce his own meanings into the analysis.

Praxeology provides laws about human action, but these laws must be combined with the meaning of the lives of individuals in order to decode concrete human actions. In economics, the locomotive of human actions consists of values (the meaning of existence) and behind the locomotive come the wagons represented by human actions. Praxeology is an objective maid of axiology and ethics. It can be boldly stated that it is the values themselves that direct the scientist's gaze to the discovery of certain laws.

The economist does not have to uphold certain values. The economist only provides information and scientific tools absolutely necessary for the pursuit of certain purposes. The economist must be honest in his search for the truth. Scientific instruments must be based on the responsibility of coherence in the search for truth.

In the search for truth, value judgments are not statements of a transcendent and omniscient entity but must be subjected to critical thinking and evaluation. For example, Mises, who declared himself a utilitarian in terms of ethics, expressed only one value judgment: that he wanted to fulfill the goals of the majority, but did not specify what they were. Mises declared himself in favor of peace, prosperity, wealth. Adherent to subjective ethics and unwilling to advance value judgments, he only wanted to achieve the goals of the masses, but without naming them. For Mises as a utilitarian, reason cannot establish ethical principles. These can only be established through subjective emotions. In order to support a laissez-faire economy and the free market, more than praxeology and utilitarian liberalism are needed to build an objective ethic.

\section{Austrian school-economic system of thought}

Kuhn's previous period was described by the position of positivists who focused on the logical architecture of scientific theories and the connection with empirical reality. From the positivist empiricists who delimited everything possible in the most distinct areas, the transition was easily made to the implicit statement that absolutely certain knowledge is an ideal to which we must strive, but we never reach it.

Every system of thought that presents reality has included in it an ontology, a plan for the nature of reality. It is important to establish on the basis of the ontology we adopt, how we can accumulate knowledge. Variants are: by reason, ie by Kantianism, by the senses representing the empirical theories or a combination of the two. The two ontological and epistemological planes 
give us a perspective of economic truth. Over time, economists have used induction, deduction, testing, experimentation.

One of the most important conceptions of SA is that of spontaneous order, ie institutions social entities are formed as a result of human action and not of conscious planning action. Thus, the theory of spontaneous order developed by Hayek analyzes the human action phenomena that do not have a single rational plan over all the actors involved and especially studies the results of such a process. A.S. pursues the intentional and unintended consequences of human action; action that takes place with a purpose; thus a spontaneous order represented by institutions appears (Hayek, 1998).

All civilizations except capitalism have tried to strike a theoretical or practical balance. They used state force to block change, they stiffened the social structure, keeping in mind the idea that they had reached a perfect stage that did not deserve change. The result is the death of civilization (Stigler, 1941).

Menger is the first economist to introduce a priori and deductivism to develop an economic theory. Menger, like Aristotle, states the existence of essences (formal causes) of reality, and a priori statements establish links between formal causes.

There are analytical sentences that are necessarily true, they are tautological, they only develop a concept with what statements they logically imply. These sentences do not bring new knowledge; there are relationships between concepts. There are synthetic sentences, which make statements about empirical reality, they represent new knowledge. An ideal in knowledge would be a priori synthetic judgment. Rothbard is a follower of radical a priori, he states that the statements deduced from a priori axioms cannot be tested and are not necessary because their truth is obviously true.

Menger rejects the use of mathematics in economics on the grounds that economics studies formal causes (essences) and not interdependencies. Menger prefers deductive and causal development to mathematical formalism.

\section{Austrian School and the science of knowledge}

A.S. takes the human sciences out of the magic of mathematics. The envy that researchers of the human sciences feel towards physics and mathematics makes the argument of economists become more and more imbued with formulas. A classic economics textbook today looks more and more like a physics textbook. The result: an ideational impoverishment. Has the economy thus become strong in predictions? Not at all. It has remained a socio-human science that can only explain the past and at most give certain tendencies towards the future. Mathematics in economics is just a game of intellectual pride. Science and mathematics itself are full of paradoxes (even in the basics), but these sciences know very well how to dump their garbage under the rug. At an in-depth look, the exact sciences have the same dogmas and paradoxes as religions and myths (Negulescu, 1969).

The work of the Oxford mathematician Roger Penrose in the field of the human mind tries to prove that the human mind does not work mathematically (Penrose, 1989). He was ridiculed by the apostles of Artificial Intelligence. But achievements in the field of AI are advancing hard and we can even say that they are blocked. A.I. has only very good marketing and very optimistic books about the future achievements of scientists with public visibility. At a close and deep look things go very hard, almost stagnant. Why? Because we don't know how the human brain works and we only have vague suspicion (Barrow \& Frank, 1986). All attempts to associate the brain and its functioning with various mathematical and physical constructs have 
yielded very poor results. Things that a person does naturally for an AI is a huge consumption of resources. Physico-chemical reactions in the human brain are not thoughts. Science has only found explanations for human reactions that are trivial and simple. The outlook for AI and neuroscience is far from optimistic. Because we do not understand the human brain nor can we reproduce it. AI is just an attempt to reconstruct the functions of human intelligence in parallel using mathematical and physical methods. No matter what devices we look at a brain with, our thoughts will never be seen (Penrose, 1994).

Thus, A.S. supplemented the mathematical desert with the richness of human thoughts and feelings. The mind does not work mathematically and deterministically. Society is not a deterministic physicalist organization; it is not a car. A.S. has recognized the limits of the sociohuman sciences. A.S. acknowledged that we can only draw the future in certain trends. Theory admits the limitations of knowledge about man. A man does not act chaotically. Man acts within certain institutions. His way of being is given by the innate abilities, the culture in which he develops (the information system in which he grows). His actions are understood in terms of his target and his plans. They can change, they are not fixed. Man is the being who shapes himself, understands himself, perfects himself according to transcendental ideals or according to a factual situation (Soto, 2006).

Hayek highlights the group's intelligence. During the evolution of a group, it transfers more and more of its actions to the institutional areas. Institutions are automated mechanisms of a kind of subconscious of the group that carries out uncreative work. The group only needs to be consciously concerned with new activities. These in turn will at some point be transferred to the automated area. An individual is limited, but the group as a whole enjoys unlimited resources (Hayek, 1973).

Among the ideational pillars of Austrian thought we want to list: man acts; utility is subjective; prices are formed only on the market; the market is linked to private property; planning a human society is impossible; time matters (time preference is important); the initiative is materialized by entrepreneurs; the consumer is the king; the result of good expectations is profit; the action is oriented towards monetary calculation; interest is related to the function of time in the economy; work includes disutility; only the salary is due to the worker; power is about politics; credit expansion equals erroneous investments; money out of nothing, they destroy the economy; taxes erroneously distribute revenues; the ideal society is a society of owners (Mises, 1957).

\section{Implications, further research and recommendations}

In the light of those presented above, we consider that economic science must remain a sociohuman science in which narrative argumentation predominates; argumentation based on obvious axioms and developed in logical steps; steps necessarily connected to each other. Mathematics must be used with great care. If we replace the narrative description with the mathematical one, we only falsify the reality, we transform it into a caricature of reality. Quantitative parameters are relevant to certain aspects of economic reality, but are really useful only inserted in an explicit narrative argument (Andrew \& Melsen, 1953). Quantities support qualitative explanations, but they are not essential to them. Cutting the quantitative indices from reality must be done modestly. Economics has a long history of using the same indices to support opposing theories. Hasty generalizations based on certain momentary statistical links between indices have led to wrong analyzes (Keyneseism is an example). 
Philosophy remains the queen of the socio-human sciences. The thinking and understanding of life by a great generality offered by philosophy orients the light of thought in the direction of economic truth (Ayer, 1956). The complex economic world is a huge tree in which the statistical indices comprise a small and perhaps insignificant part, and the economicphilosophical thinking of the Austrian school includes the tree as a whole. Philosophy and its type of systematic and general thinking must remain an important concern for economists. The current type of thinking in the sciences in which more and more small things are studied leads to a misunderstanding of the economic world or its perversion through irrelevant marginal aspects. (Ex: critique of capitalism from the perspective of socialism). Socialism cuts out the marginal, negative aspects of capitalism, separates them from the whole, criticizes them, and then generalizes them.

The power of prediction in the socio-human sciences is limited. We can understand the past in terms of motives, but the future is unencodable. Small differences in a society and contingency are essential for the future. We cannot know in advance what is the small aspect that will matter in the subsequent evolution of society. At the same time, we can say with certainty that private property and political decentralization are the key to a better future (Blaug, 1980).

How can we use what is stated in this article? Through a devastating critique of socialism; socialism that is becoming more and more powerful. Socialism produces evils, and for these evils it accuses capitalism. The nonsense of socialism must be shown in all its nakedness and ugliness. A.S. does not say about man that he is good and society spoils him, but indicates how a society can limit the bad nature of man and even use it to evolve (Mursa, 2020). The foolish utopia of socialism and the road to this illusion create suffering. Only the type of argument presented in this article can show the lack of logical foundation of socialism and the ambitions for power behind a mask of empathy. Socialism with both Marxist and fascist facets must be analyzed in all its aspects (Mursa, 2020). This analysis can only be based on the type of thinking presented in this article. This article is a first step towards the critique of socialism and the defense of capitalism.

\section{Conclusion}

In addition to individualism and methodological subjectivism, Austrian thinking is also characterized by: bending over marginalism; decreasing marginal utility; opportunity cost; transmitting the value of a good to complementary factors; disregarding the mathematical and empirical method in the study of economics. For Austrians, the economy is an open concept that emphasizes: free choice, limited knowledge, uncertainty, the evolution of economic processes. The Austrians support freedom and minimal state intervention and reject empiricist positivism.

Human actions are meaningful actions, each act has its own meaning, ie it has a certain purpose. An action is the materialization of the values in which the one who acts believes. Depending on his value judgments, a person chooses his goals and means for that purpose. Abilities, aptitudes, knowledge determine a person to choose one goal or another. The values adopted prioritize the goals, and the action plans are forward-looking with inherent risk-taking and uncertainty. It takes empathy on the part of one who studies human action to understand why people act. That is, the context and motivation of the person acting is mentally recreated. Without empathy, scientific autism is directly and simply reached; movements are seen, but the formal cause and the final cause are not understood; concepts cannot be identified but only chaotic movements (Chisholm, 1977). 
People act because they are dissatisfied with a state of affairs. People carry out actions in a state of partial knowledge of the context in which they carry out their action and of limited powers of action. Any action aims to improve the situation. People act, this is the state to which they are forced by their human condition. Menger recognizes that not all human ends are economic, and a total human understanding can only be achieved by all the social sciences together; sciences that approach man from multiple angles (Menger, 2016).

We will never be able to know the future. People's intentions change, the interaction between people builds unknown social configurations. Mathematics cannot reproduce the richness of inner feelings, and the motivation of profit is only one of the motivations (Damasio, 2006). Social freedom builds connections between individuals and flows that result in hierarchical social architectures with unsuspected configurations. Trying to create social engineers according to well-established plans only leads to widespread impoverishment. No individual or group can anticipate all the intentions and spontaneous connections between individuals that form and lead to the construction of social configurations. The architecture of the social system is constantly changing, we can only witness its change and partially understand this change only after it has taken place. Forcing the social structure in one direction or another (according to a predetermined plan) only impoverishes it from the richness of the connections that would have appeared spontaneously. We must be modest in understanding the social system. It depends on individuals who are not simple atoms with passive behavior determined only from the outside but are active and the engine is inside them, and this engine can only be suspected. Individuals differ in all respects including the ability to connect with others (Damasio, 2010). And this capacity forms the configuration of the social system. The conclusion: the freedom of individuals leads to the richness of the social system.

\section{References}

Andrew, G., \& Melsen, V. (1953). The Philosophy of Nature, Pittsburgh, Duguesne University Press.

Ayer, A.J. (1956). The Problem of Knowledge, Harmondsworth, Penguin Books.

Barrow, J.D., \& Frank, J.T. (1986). The Antropic Cosmological Principle, London, Oxford University Press.

Blaug, M. (1980). The Methodology of Economics or how Economists Explain, Cambridge, Cambridge University Press.

Bratianu, C., Bejinaru, R. (2019). The Theory of Knowledge Fields: A Thermodynamics Approach. Systems 2019, 7, 20.

Chisholm, R.M. (1977). Theory of Knowledge, New Jersey, Prentice Hall.

Damasio, A. (2006). Descarte's error. London: Vintage Random House.

Damasio, A. (2010). Looking for Spinoza. Joy, Sorrow and Feeling Brain, London, Vintage Random House.

Descartes, R. (1990). Discurs asupra metodei, București, Editura Academiei.

Hayek, F. (1949). Individualism and Economic Order, London, Routledge.

Hayek, F. (1998). Prices and Production, London, Routledge.

Hayek, F. (1973). Law, Legislation and Liberty, London, Routledge.

Hume, D. (1987). Cercetare asupra intelectului omenesc, București, Editura științifică și enciclopedică.

Kirzner, I. (1996). Perspectiva economică, București, All.

Menger, C. (2016). Principiile economiei, Iasi, Liberalis. 
Mises, von L. (1957). Theory and History, New Haven, Yale University Press.

Mises, von L. (1966). Human Action, Chicago, Henry Regnery.

Mises, von L. (1981). Epistemological Problems of Economics, New York, New York University Press.

Mises, von L. (2006). The causes of the economic crisis, Alabama, Ludwig Von Mises Institute.

Mises, von L. (2009). The Theory of Money and Credit, Alabama, Ludwig Von Mises Institute.

Mursa, G. (2020). Liberalismul, Iasi, Liberalis.

Mursa, G. (2020). Ordinea economic a societății libere, Iasi, Liberalis.

Negulescu, P.P. (1969). Problema cunoașterii, București, Editura Academiei.

Penrose, R. (1994). The Emperor's New Mind. Concerning Computers, Minds, and the Lows of Physic, London, Oxford University Press.

Penrose, R. (1989). Shadows of the Mind, London, Oxford University Press.

Rothbard, M.N. (1977). Man, Economy, and State with Power and Market, Alabama, Ludwig Von Mises Institute.

Rothbard, M.N. (1997). Logic of Action: Method, Money and the Austrian School, Cheltenham, Edward Eldgar.

Rothbard, M.N. (2008). The Mystery of Banking, Alabama, Ludwig Von Mises Institute.

Say, J.B. (1964). A treatise on Political Economy, New York, Augustus M. Kelly.

Soto, H. (2006). Money, Bank Credit, and Economic Cycles, Alabama, Ludwig Von Mises Institute.

Smith, B. (1994). Austrian Philosophy, Chicago, Open Court.

Stigler, G.J. (1941). Theories of Production and Distribution, New York, Macmillan.

Wright, von G.H. (1971). Explanation and Under Standing, New Yorg, Cornell University Press. 